\title{
IMPACT OF THE IMPERFECT POLARIZING-BEAM SPLITTER AND QUARTER-WAVE PLATE AND NON-IDEAL LASER BEAM ON THE ACCURACY OF NANO-DISPLACEMENT LASER ENCODER
}

\author{
Saeed Olyaee ${ }^{1}$, Abdollah Gorgani Firoozjah ${ }^{2}$ \\ 1,2Nano-photonics and Optoelectronics Research Laboratory (NORLab), Faculty of Electrical Engineering, Shahid \\ Rajaee Teacher Training University, Tehran, Iran \\ Email: solyaee@srttu.edu
}

\begin{abstract}
In this paper, periodic nonlinear error of laser encoder for nano-displacement measurement caused by imperfection of polarizing-beam splitter (PBS), quarter-wave plate (QWP), and laser source is modeled by using the Jones matrix analysis. The results reveal that the peak-topeak nonlinearity resulting from imperfect PBS and QWP, and non-orthogonality and ellipticity of the polarized laser beams is obtained as $14.82 \mathrm{~nm}$. Also, considering typical values of transmittance and reflectance coefficients of PBS and different retardation errors of QWP, the first-order and second-order nonlinearities are respectively revealed resulting from imperfect PBS and QWP.
\end{abstract}

Keywords: Jones matrix, nano-displacement, nonlinearity error, polarizing-beam splitter, nanometrology, quarter-wave plate.

\section{NOMENCLATURE}

\begin{tabular}{|c|c|c|c|}
\hline PBS & Polarizing-beam splitter & $\mathbf{T}_{\mathrm{i}}$ & Transmittance matrix of $i^{\text {th }} P B S$ \\
\hline QWP & Quarter-wave plate & $\delta$ & Non-orthogonality \\
\hline BS & Beam splitter & $\mathbf{R}_{\mathbf{i}}$ & Reflectance matrix of $\mathrm{i}^{\text {th }}$ PBS \\
\hline $\mathbf{Q}_{45^{\circ}}$ & Quarter wave plate with fast axis $45^{\circ}$ & IPDi & Photocurrent of $\mathrm{i}^{\text {th }}$ photodetector \\
\hline $\mathbf{Q}_{0^{\circ}}$ & Quarter wave plate with fast axis $0^{\circ}$ & $\mathbf{E}_{\mathbf{P D}_{i}}$ & $\begin{array}{l}\text { Electric field of incident beam on } \mathrm{i}^{\text {th }} \\
\text { photodetector }\end{array}$ \\
\hline PD & Photodetector & $\Delta \varphi$ & Phase difference \\
\hline QPD & Quadrant photodetector & $\Delta x$ & $\mathrm{X}$-direction displacement \\
\hline$\Psi$ & Diffraction angle & $\mathbf{E}$ & Electric field matrix of laser beam \\
\hline$\varepsilon$ & Retardation error of QWP & $\overline{\mathbf{E}_{\mathbf{P D}_{i}}}$ & Transpose of electric field matrix on $P D_{i}$ \\
\hline
\end{tabular}

\section{Introduction}

LASER Measurement in nano-scale is one of the fundamental necessities for high precision industries such as semiconductor manufactories and machine tools. Nano-metrology in semiconductor industry is used for photolithography machines and semiconductor inspection tools. Photolithography machines are used for making nano-scale transistor patterns on wafers with absolute accuracy. These machines require that measure the position of wafer stages in six axes with sub-nanometer uncertainty [1].

There are two types of displacement for each stage; translational displacement and rotational displacement.

Linear displacement in $\mathrm{x}, \mathrm{y}$, and $\mathrm{z}$ directions are introduced by $\Delta x, \Delta y$ and $\Delta z$ [2], and rotational displacements in same axes are introduced with pitch, yaw, and roll. Interferometer and autocollimator are respectively used for measurement the linear and angular displacements [3]-[6]. But the laser encoder can measure both linear and angular displacement, simultaneously. Optical path-dependent. 
Some important error sources can be categorized as installation error, optics errors, electronics error, and environmental error [7]-[9]. The main part of uncertainty for measurement equipment is periodic nonlinear error. Nonlinearity in laser interferometers has been modeled by several methods such as Jones matrix analysis, neural networks, and adaptive algorithms [10]-[13]. The nonlinear errors can arise with imperfection of optical components such as polarizing-beam splitters (PBSs), quarter-wave plates (QWPs), and laser source [14]-[16].

We have investigated, modelled, and simulated the periodic nonlinear error of the laser encoder by considering non-ideal PBS and QWP [17]. Then, imperfect polarized laser beam has been considered as an error source in laser encoder [18]-[19]. Here, we investigate the nonlinearity considering all error parameters including imperfect PBS and QWP and non-orthogonality and ellipticity of the polarized laser beams. The rest of the paper is categorized as follows: A configuration of laser encoder is investigated in section 2 . The Jones calculus method for obtaining the nonlinearity and simulation results are described in section 3 [17]-[20]. Finally, a conclusion is drawn in the last section.

\section{Configuration of laser encoder}

A configuration of a laser encoder is illustrated in Figure 1 [17]-[20]. According to this figure, the laser beam with wavelength $\lambda$ projected on polarizing beam splitter (PBS1). In ideal case, s-polarized beam with amplitude $\beta$ is reflected by PBS and projected on scale grating with grating period of $g$. The incident beams on scale grating are diffracted with angle of $\pm \psi$. The p-polarized beams with amplitude $\alpha$ are passed through $\mathrm{PBS}_{1}$ and projected on reference grating. The incident beams on reference grating are diffracted with angle of $\pm \psi$. The negative and positive diffracted beams from two gratings with diffraction angle $\psi$ are bent by prisms and superimposed to generate interference signals. The interference signals are divided into four sub wave

$$
\mathbf{E}_{\mathbf{A}}=\left[\mathbf{T}_{1} \mathbf{Q}_{45^{\circ}} \exp (\mathrm{i} \Delta \varphi) \mathbf{Q}_{45^{\circ}} \mathbf{R}_{\mathbf{1}}+\mathbf{R}_{\mathbf{1}} \mathbf{Q}_{45^{\circ}} \mathbf{Q}_{45^{\circ}} \mathbf{T}_{1}\right] \mathbf{E}
$$

Now, we write the Jones matrix of electric field of beams after they passed through $\mathrm{PBS}_{1}$ as Eq. (2):

When the scale grating on the stage moves as a displacement of $\Delta \mathrm{x}$ along the $\mathrm{x}$-axis and $\Delta \mathrm{z}$ along the $\mathrm{z}$-axis, these displacements causes phase difference on positive and negative first order diffracted beams, respectively, due to the Doppler effect as follows [21]-[22]:

$$
\Delta \varphi=\frac{2 \pi}{\mathrm{g}} \Delta \mathrm{x}+\frac{2 \pi}{\lambda}(1+\cos \psi) \Delta \mathrm{z}
$$

where, $\mathbf{T}$ and $\mathbf{R}$ are the transmittance and reflectance matrices of PBS, respectively, $\mathbf{Q}_{45^{\circ}}$ and $\mathbf{Q}_{0^{\circ}}$ are the Jones matrix of quarter-wave plates with fast axis at $45^{\circ}$ and $0^{\circ}$, respectively, and $\mathbf{E}$ is the electric field of laser beam with s- and ppolarizations [6], [14]: 


$$
\begin{aligned}
& \mathbf{T}=\left[\begin{array}{cc}
\mathrm{T}_{\mathrm{P}} & 0 \\
0 & \mathrm{~T}_{\mathrm{S}}
\end{array}\right], \mathbf{R}=\left[\begin{array}{cc}
\mathrm{R}_{\mathrm{P}} & 0 \\
0 & \mathrm{R}_{\mathrm{S}}
\end{array}\right] \\
& \mathbf{Q}_{45^{\circ}}=\frac{1}{\sqrt{2}}\left[\begin{array}{cc}
1-\frac{\varepsilon}{2} & -\mathrm{i}\left(1+\frac{\varepsilon}{2}\right) \\
-\mathrm{i}\left(1+\frac{\varepsilon}{2}\right) & 1-\frac{\varepsilon}{2}
\end{array}\right], \mathbf{Q}_{0^{\circ}}=\frac{1}{\sqrt{2}}\left[\begin{array}{cc}
(1-\mathrm{i})\left(1-\frac{\varepsilon}{2}\right) & 0 \\
0 & (1+\mathrm{i})\left(1-\frac{\varepsilon}{2}\right)
\end{array}\right] \\
& \mathbf{E}=\left[\begin{array}{l}
\mathrm{E}_{\mathrm{x}} \\
\mathrm{E}_{\mathrm{y}}
\end{array}\right]=\left[\begin{array}{c}
1-\mathrm{ibexp}(\mathrm{i} \delta) \\
1+\mathrm{ibexp}(\mathrm{i} \delta)
\end{array}\right]
\end{aligned}
$$

And $\varepsilon$ is the retardation error of quarter wave plate, $\mathrm{b}$ and $\delta$ are non-orthogonality and ellipticity of polarized laser beam, respectively. The electric fields of incident beam on each photodetector $\left(\mathrm{PD}_{1}-\mathrm{PD}_{4}\right)$ are calculated as follow [17]:

$$
\begin{aligned}
& \mathbf{E}_{\mathbf{P D}_{1}}=\frac{1}{\sqrt{2}} \mathbf{T}_{2} \mathbf{Q}_{45^{\circ}} \mathbf{E}_{\mathrm{A}}, \mathrm{I}_{\mathrm{PD}_{1}}=\mathbf{E}_{\mathbf{P D}_{1}} \cdot \overline{\mathbf{E}_{\mathbf{P D}_{1}}} \\
& \mathbf{E}_{\mathbf{P D}_{2}}=\frac{1}{\sqrt{2}} \mathbf{R}_{2} \mathbf{Q}_{45^{\circ}} \mathbf{E}_{\mathrm{A}}, \mathrm{I}_{\mathrm{PD}_{2}}=\mathbf{E}_{\mathbf{P D}_{2}} \overline{\mathbf{E}_{\mathbf{P D}_{2}}} \\
& \mathbf{E}_{\mathrm{PD}_{3}}=\frac{1}{\sqrt{2}} \mathbf{T}_{3} \mathbf{Q}_{45^{\circ}} \mathbf{Q}_{0^{\circ}} \mathbf{E}_{\mathrm{A}}, \mathrm{I}_{\mathrm{PD}_{3}}=\mathbf{E}_{\mathrm{PD}_{3}} \cdot \overline{\mathbf{E}_{\mathbf{P D}_{3}}} \\
& \mathbf{E}_{\mathbf{P D}_{4}}=\frac{1}{\sqrt{2}} \mathbf{R}_{3} \mathbf{Q}_{45^{\circ}} \mathbf{Q}_{0^{\circ}} \mathbf{E}_{\mathrm{A}}, \mathrm{I}_{\mathrm{PD}_{4}}=\mathbf{E}_{\mathbf{P D}_{4}} \cdot \overline{\mathbf{E}_{\mathbf{P D}_{4}}}
\end{aligned}
$$

By substitution of relative Jones matrices in Eqs. (2), (6)-(9), photocurrent of the first photodetector is obtained by:

$$
\mathrm{I}_{\mathrm{PD} 1}=\frac{1}{4}\left[\frac{1}{2}\left(\mathrm{~A}_{1}{ }^{2}+\mathrm{A}_{2}{ }^{2}+\mathrm{A}_{3}{ }^{2}+\mathrm{A}_{4}{ }^{2}\right)+\left(-\mathrm{A}_{1} \mathrm{~A}_{2}+\mathrm{A}_{3} \mathrm{~A}_{4}\right) \sin \left(\theta_{1}-\theta_{2}\right)\right]
$$

where,

$$
\begin{aligned}
& \mathrm{A}_{1} \triangleq \mathrm{T}_{\mathrm{P}}\left(1-\frac{\varepsilon}{2}\right) \sqrt{\mathrm{n}_{1}^{2}+\mathrm{n}_{2}^{2}} \\
& \mathrm{~A}_{2} \triangleq \mathrm{T}_{\mathrm{P}}\left(1+\frac{\varepsilon}{2}\right) \sqrt{\mathrm{n}_{3}^{2}+\mathrm{n}_{4}{ }^{2}} \\
& \mathrm{~A}_{3} \triangleq \mathrm{T}_{\mathrm{s}}\left(1+\frac{\varepsilon}{2}\right) \sqrt{\mathrm{n}_{1}^{2}+\mathrm{n}_{2}^{2}} \\
& \mathrm{~A}_{4} \triangleq \mathrm{T}_{\mathrm{s}}\left(1-\frac{\varepsilon}{2}\right) \sqrt{\mathrm{n}_{3}{ }^{2}+\mathrm{n}_{4}{ }^{2}} \\
& \mathrm{n}_{1} \triangleq \alpha \mathrm{R}_{\mathrm{p}} \mathrm{T}_{\mathrm{p}} \varepsilon[(1+\cos \Delta \varphi)(1+\mathrm{b} \sin \delta)+\mathrm{b} \sin \Delta \varphi \cos \delta] \\
& -\beta\left(1-\frac{\varepsilon^{2}}{4}\right)\left[\left(\mathrm{R}_{\mathrm{S}} \mathrm{T}_{\mathrm{P}} \sin \Delta \varphi\right)(1-\mathrm{b} \sin \delta)+\mathrm{b} \cos \delta\left(\mathrm{R}_{\mathrm{S}} \mathrm{T}_{\mathrm{P}} \cos \Delta \varphi+\mathrm{R}_{\mathrm{P}} \mathrm{T}_{\mathrm{S}}\right)\right] \\
& \mathrm{n}_{2} \triangleq \alpha \mathrm{R}_{\mathrm{p}} \mathrm{T}_{\mathrm{p}} \varepsilon[\sin \Delta \varphi(1+\mathrm{b} \sin \delta)-\mathrm{b} \cos \delta(1+\cos \Delta \varphi)] \\
& +\beta\left(1-\frac{\varepsilon^{2}}{4}\right)\left[\left(\mathrm{R}_{\mathrm{S}} \mathrm{T}_{\mathrm{P}} \cos \Delta \varphi+\mathrm{R}_{\mathrm{P}} \mathrm{T}_{\mathrm{S}}\right)(1-\mathrm{b} \sin \delta)-\left(\mathrm{R}_{\mathrm{S}} \mathrm{T}_{\mathrm{P}} \cos \Delta \varphi+\mathrm{R}_{\mathrm{P}} \mathrm{T}_{\mathrm{S}}\right) \mathrm{b} \cos \delta\right. \\
& \mathrm{n}_{3} \triangleq \alpha\left(1-\frac{\varepsilon^{2}}{4}\right)\left[\left(\mathrm{R}_{\mathrm{P}} \mathrm{T}_{\mathrm{S}} \cos \Delta \varphi+\mathrm{R}_{\mathrm{S}} \mathrm{T}_{\mathrm{P}}\right) \mathrm{b} \cos \delta-\mathrm{R}_{\mathrm{P}} \mathrm{T}_{\mathrm{S}} \sin \Delta \varphi(1+\mathrm{b} \sin \delta)\right] \\
& +\beta \mathrm{R}_{\mathrm{s}} \mathrm{T}_{\mathrm{s}} \varepsilon[(1+\cos \Delta \varphi)(1-\mathrm{b} \sin \delta)-\mathrm{b} \cos \delta \sin \Delta \varphi]
\end{aligned}
$$




$$
\begin{aligned}
\mathrm{n}_{4} \triangleq & \alpha\left(1-\frac{\varepsilon^{2}}{4}\right)\left[\left(\mathrm{R}_{\mathrm{P}} \mathrm{T}_{\mathrm{S}} \cos \Delta \varphi+\mathrm{R}_{\mathrm{S}} \mathrm{T}_{\mathrm{P}}\right)(1+\mathrm{b} \sin \delta)+\mathrm{R}_{\mathrm{P}} \mathrm{T}_{\mathrm{S}} \sin \Delta \varphi \mathrm{bcos} \delta\right] \\
& +\beta \mathrm{R}_{\mathrm{s}} \mathrm{T}_{\mathrm{s}} \varepsilon[\sin \Delta \varphi(1-\mathrm{b} \sin \delta)+\mathrm{b} \cos \delta(1+\cos \Delta \varphi)] \\
\theta_{1}= & \arctan \left(\frac{\mathrm{n}_{1}}{\mathrm{n}_{2}}\right) \\
\theta_{2}= & \arctan \left(\frac{\mathrm{n}_{3}}{\mathrm{n}_{4}}\right)
\end{aligned}
$$

Eq. (11) is used for calculation of the photocurrent of the second photodetector:

$$
\mathrm{I}_{\mathrm{PD} 2}=\frac{1}{4}\left[\frac{1}{2}\left(\mathrm{~B}_{1}^{2}+\mathrm{B}_{2}^{2}+\mathrm{B}_{3}^{2}+\mathrm{B}_{4}^{2}\right)+\left(-\mathrm{B}_{1} \mathrm{~B}_{2}+\mathrm{B}_{3} \mathrm{~B}_{4}\right) \sin \left(\theta_{1}-\theta_{2}\right)\right]
$$

where,

$$
\begin{aligned}
& \mathrm{B}_{1} \triangleq \mathrm{R}_{\mathrm{P}}\left(1-\frac{\varepsilon}{2}\right) \sqrt{\mathrm{n}_{1}^{2}+\mathrm{n}_{2}^{2}} \\
& \mathrm{~B}_{2} \triangleq \mathrm{R}_{\mathrm{P}}\left(1+\frac{\varepsilon}{2}\right) \sqrt{\mathrm{n}_{3}^{2}+\mathrm{n}_{4}^{2}} \\
& \mathrm{~B}_{3} \triangleq \mathrm{R}_{\mathrm{s}}\left(1+\frac{\varepsilon}{2}\right) \sqrt{\mathrm{n}_{1}^{2}+\mathrm{n}_{2}^{2}} \\
& \mathrm{~B}_{4} \triangleq \mathrm{R}_{\mathrm{s}}\left(1-\frac{\varepsilon}{2}\right) \sqrt{\mathrm{n}_{3}^{2}+\mathrm{n}_{4}^{2}}
\end{aligned}
$$

Third photodetector has a cosine equation for photocurrent that is obtained by:

$$
\mathrm{I}_{\mathrm{PD} 3}=\frac{1}{4}\left[\frac{1}{2}\left(\mathrm{C}_{1}{ }^{2}+\mathrm{C}_{2}{ }^{2}+\mathrm{C}_{3}{ }^{2}+\mathrm{C}_{4}{ }^{2}\right)+\left(\mathrm{C}_{1} \mathrm{C}_{2}-\mathrm{C}_{3} \mathrm{C}_{4}\right) \cos \left(\theta_{1}-\theta_{2}\right)\right]
$$

where,

$$
\begin{aligned}
& \mathrm{C}_{1} \triangleq \mathrm{T}_{\mathrm{P}}\left(1-\frac{\varepsilon}{2}\right)^{2} \sqrt{\mathrm{n}_{1}{ }^{2}+\mathrm{n}_{2}{ }^{2}} \\
& \mathrm{C}_{2} \triangleq \mathrm{T}_{\mathrm{P}}\left(1-\frac{\varepsilon^{2}}{4}\right) \sqrt{\mathrm{n}_{3}^{{ }^{2}+\mathrm{n}_{4}{ }^{2}}} \\
& \mathrm{C}_{3} \triangleq \mathrm{T}_{\mathrm{s}}\left(1-\frac{\varepsilon^{2}}{4}\right) \sqrt{\mathrm{n}_{1}^{{ }^{2}+\mathrm{n}_{2}{ }^{2}}} \\
& \mathrm{C}_{4} \triangleq \mathrm{T}_{\mathrm{s}}\left(1-\frac{\varepsilon}{2}\right)^{2} \sqrt{\mathrm{n}_{3}{ }^{2}+\mathrm{n}_{4}{ }^{2}}
\end{aligned}
$$

The photocurrent of forth photodetector is calculated as follow:

$$
\mathrm{I}_{\mathrm{PD} 4}=\frac{1}{4}\left[\frac{1}{2}\left(\mathrm{D}_{1}^{2}+\mathrm{D}_{2}^{2}+\mathrm{D}_{3}^{2}+\mathrm{D}_{4}^{2}\right)+\left(\mathrm{D}_{1} \mathrm{D}_{2}-\mathrm{D}_{3} \mathrm{D}_{4}\right) \cos \left(\theta_{1}-\theta_{2}\right)\right]
$$

where,

$$
\mathrm{D}_{1}=\mathrm{R}_{\mathrm{P}}\left(1-\frac{\varepsilon}{2}\right)^{2} \sqrt{\mathrm{n}_{1}^{2}+\mathrm{n}_{2}^{2}}
$$




$$
\begin{aligned}
& \mathrm{D}_{2}=\mathrm{R}_{\mathrm{p}}\left(1-\frac{\varepsilon^{2}}{4}\right) \sqrt{\mathrm{n}_{3}{ }^{2}+\mathrm{n}_{4}{ }^{2}} \\
& \mathrm{D}_{3}=\mathrm{R}_{5}\left(1-\frac{\varepsilon^{2}}{4}\right) \sqrt{\mathrm{n}_{1}{ }^{2}+\mathrm{n}_{2}{ }^{2}} \\
& \mathrm{D}_{4}=\mathrm{R}_{5}\left(1-\frac{\varepsilon}{2}\right)^{2} \sqrt{\mathrm{n}_{3}{ }^{2}+\mathrm{n}_{4}{ }^{2}}
\end{aligned}
$$

On the basis of the ideal condition, that $\mathrm{T}_{\mathrm{P}}=\mathrm{R}_{\mathrm{S}}=1, \mathrm{R}_{\mathrm{P}}=\mathrm{T}_{\mathrm{S}}=0$, and $\varepsilon=\mathrm{b}=\delta=0$, Eqs. (10)-(13) are simplified as:

$$
\begin{aligned}
& \mathrm{I}_{\mathrm{PD}_{1}}=\mathrm{u}_{0}{ }^{2}[1-\sin \Delta \varphi] \\
& \mathrm{I}_{\mathrm{PD}_{2}}=\mathrm{u}_{0}{ }^{2}[1+\sin \Delta \varphi] \\
& \mathrm{I}_{\mathrm{PD}_{3}}=\mathrm{u}_{0}{ }^{2}[1+\cos \Delta \varphi] \\
& \mathrm{I}_{\mathrm{PD}_{4}}=\mathrm{u}_{0}{ }^{2}[1-\cos \Delta \varphi]
\end{aligned}
$$

We use arctangent method for calculation of the phase difference caused by displacement and non-linearity from polarizing-beam splitter [6]:

$$
\begin{aligned}
& \mathrm{T}_{\mathrm{X}+1}=\frac{\mathrm{I}_{\mathrm{PD}_{2}}-\mathrm{I}_{\mathrm{PD}_{1}}}{\mathrm{I}_{\mathrm{PD}_{3}}-\mathrm{I}_{\mathrm{PD}_{4}}}=\tan \left(\Delta \varphi_{\mathrm{x}}+\Delta \varphi_{\mathrm{z}}\right) \\
& \Delta \varphi=\tan ^{-1}\left(\frac{\mathrm{I}_{\mathrm{PD}_{2}}-\mathrm{I}_{\mathrm{PD}_{1}}}{\mathrm{I}_{\mathrm{PD}_{3}}-\mathrm{I}_{\mathrm{PD}_{4}}}\right)
\end{aligned}
$$

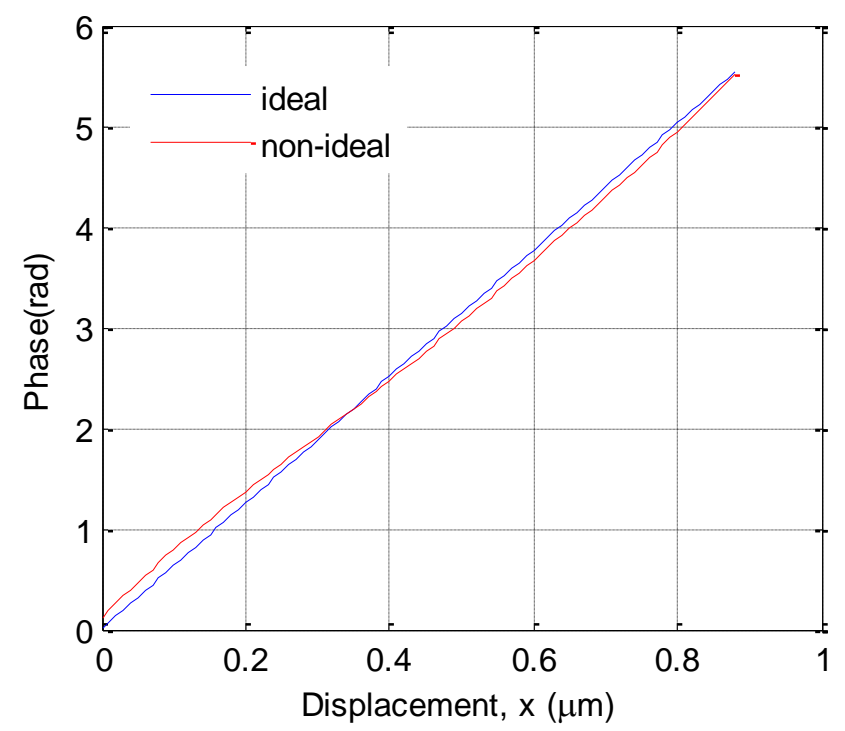

Figure 2. The phase difference of two conditions; ideal $\left(T_{P}=1, T_{S}=0, R_{P}=0, R_{S}=1, \varepsilon=0, b=0\right.$, and $\left.\delta=0^{\circ}\right)$ and non-ideal $\left(T_{P}=0.95, T_{S}=0.0001, R_{P}=0.05, R_{S}=0.998, \varepsilon=0.05, b=0.1\right.$, and $\delta=3^{\circ}$ ).

For non-ideal case we have:

$$
\theta_{1}-\theta_{2}=\tan ^{-1}\left(\frac{\mathrm{I}_{\mathrm{PD}_{2}}-\mathrm{I}_{\mathrm{PD}_{1}}}{\mathrm{I}_{\mathrm{PD}_{3}}-\mathrm{I}_{\mathrm{PD}_{4}}}\right)
$$




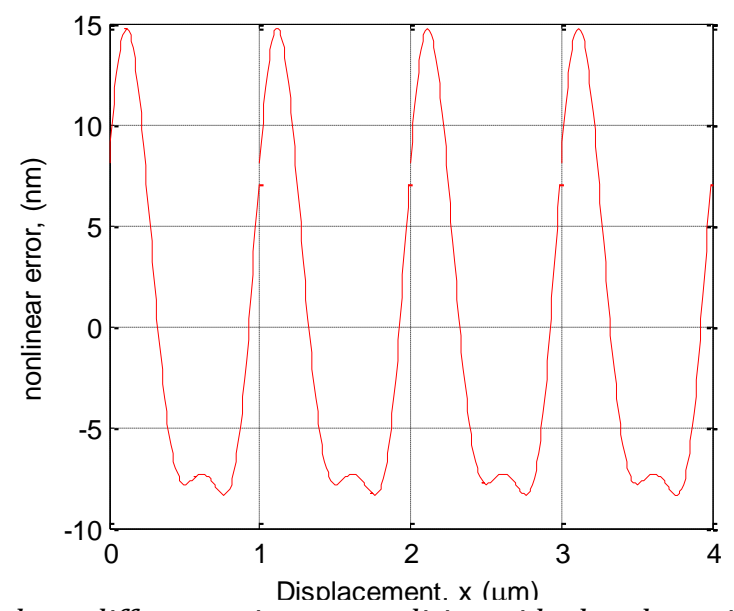

Figure 3. The subtraction of phase differences in two conditions; ideal and non-ideal $\left(T_{P}=0.95, T_{S}=0.002, R_{P}=0.05\right.$, $R s=0.998, \varepsilon=0.05, b=0.1$, and $\delta=3^{\circ}$ )

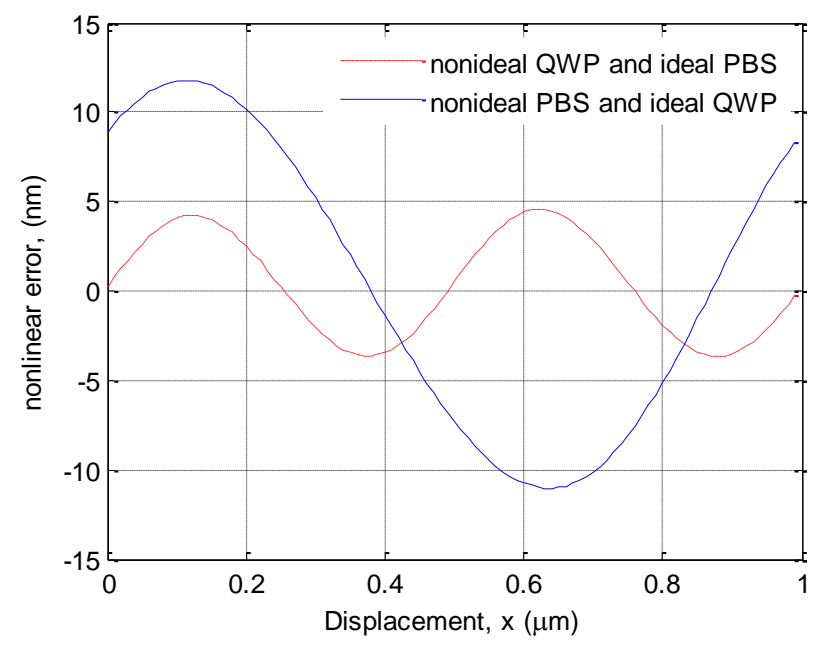

Figure 4. The nonlinear error with respect to the displacement resulting from non-ideal PBS and QWP. Continuous curve: non-ideal $P B S\left(T_{P}=0.95, T_{S}=0.002, R_{P}=0.05, R_{S}=0.998\right)$, ideal $Q W P$, ideal laser source. Dashed lines: non-ideal $Q W P(\varepsilon=0.05)$, ideal PBS, and ideal laser source.

The simulation results considering wavelength 685 $\mathrm{nm}$ and pitch of grating $1 \mu \mathrm{m}$ are shown in Figs. 2 and 3. The specifications for the PBS are as follows: the transmittance coefficients for $\mathrm{p}$ - and s-polarized beams are 0.95 and 0.002 and the reflectance coefficients for $\mathrm{p}$ - and s-polarized beams are 0.05 and 0.998 , respectively [14]. The retardation error of quarter wave plates is supposed $0.05 \mathrm{rad}$. These values mean that there is undesired optical leakage which induces the phase mixing and nonlinear error. The ellipticity $b$ that is the ratio of minor to major axes is 0.1 and non-orthogonality is $3^{\circ}$. As shown in Figure 3, it can be seen that the maximum nonlinear error is $14.82 \mathrm{~nm}$ in non-ideal condition.

The nonlinear error from non-ideal PBS $\left(\mathrm{T}_{\mathrm{P}}=0.95\right.$, $\mathrm{T}_{\mathrm{S}}=0.002, \mathrm{R}_{\mathrm{P}}=0.05$, and $\mathrm{R}_{\mathrm{S}}=0.998$ ) is simulated and plotted in Figure 4 with continues line considering ideal laser source and QWP. In this figure, the nonlinear error from non-ideal QWP $(\varepsilon=0.05)$ is plotted with dashed lines considering the ideal case for the laser source and PBS. As shown in this figure, first-order and second-order nonlinearities are happened resulting from imperfect PBS and QWP, respectively.

The simulation results for different parameters of PBS are plotted in Figs. 5 and 6, where the retardation error $\varepsilon$, ellipticity $b$, and nonorthogonality $\delta$ are supposed to be $0.05 \mathrm{rad}, 0.1$ and $3^{\circ}$, respectively. It can be seen that the main contributors of PBS parameters in nonlinearity are the transmittance coefficient for p-polarized beam and reflectance coefficient for s-polarized beam. Increasing the TP from 0.95 to 0.98 causes to decrease the nonlinear error, whereas nonlinearity is increased by increasing RS from 0.989 to 0.998 ; both cases appear as the first-order nonlinearity. The simulation results indicate that one- or twocycle error could be produced per one wavelength (1 $\mu \mathrm{m})$, depending on the non-ideal optical component. The simulation results for different retardation errors of QWP are plotted in Figure 7, where $\mathrm{T}_{\mathrm{P}}=0.95, \mathrm{~T}_{\mathrm{S}}=0.0001, \quad \mathrm{R}_{\mathrm{P}}=0.05, \quad \mathrm{R}_{\mathrm{S}}=0.998, \quad$ and 
ellipticity $\mathrm{b}$ and non-orthogonality $\delta$ are supposed to be 0.1 and $3^{\circ}$, respectively. It can be seen that the maximum nonlinearity caused by QWPs is $4 \mathrm{~nm}$ and the increment in retardation error $(\varepsilon)$ increases the nonlinearity.

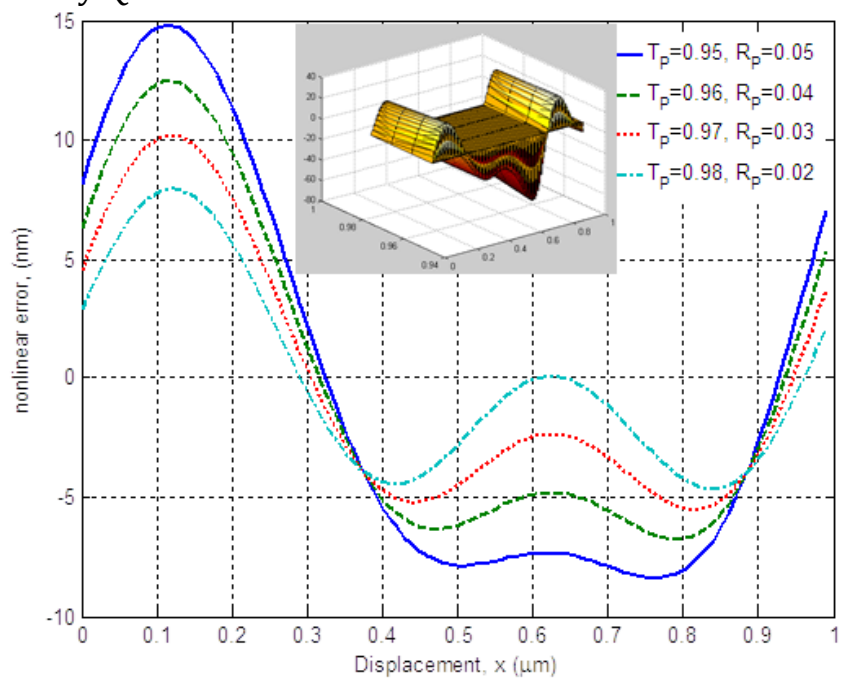

Figure 5. The nonlinear error with respect to the displacement resulting from different transmittance and reflectance coefficients $\left(T_{S}=0.002, R_{S}=0.998, \varepsilon=0.05, b=0.1\right.$, and $\left.\delta=3^{\circ}\right)$. The inset shows the $3 D$ plot of nonlinear error.

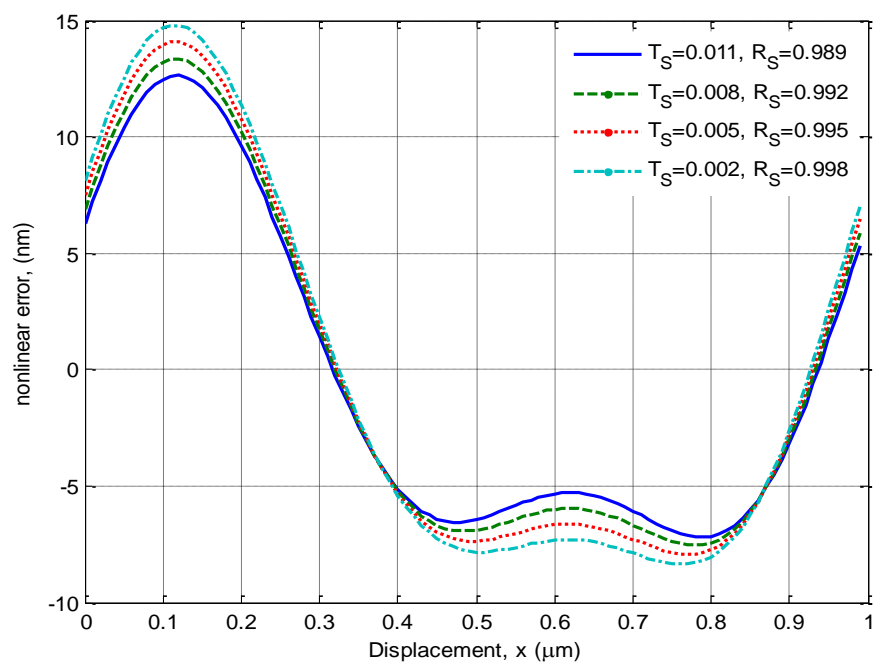

Figure 6. The nonlinear error with respect to the displacement resulting from different reflectance and transmittance coefficients $\left(T_{P}=0.95, R_{P}=0.05, \varepsilon=0.05, b=0.1\right.$, and $\delta=3^{\circ}$ ).

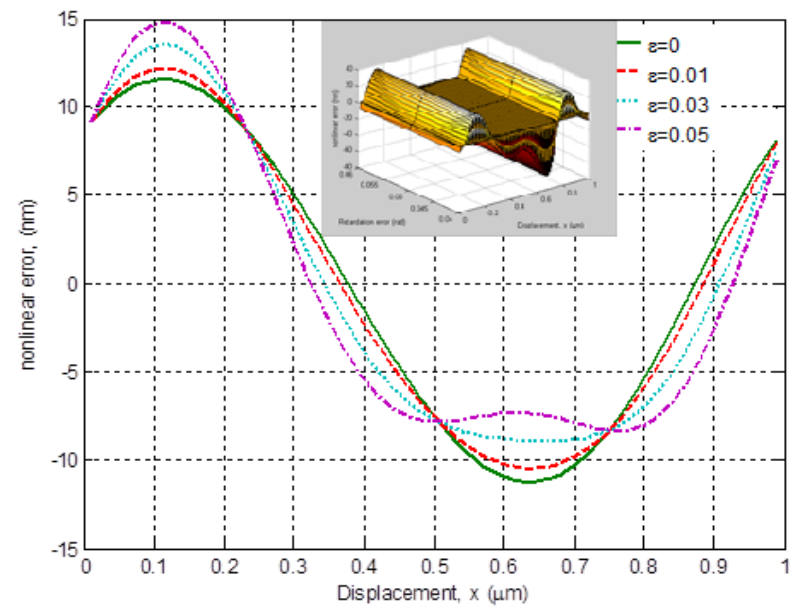

Figure 7. The nonlinear error as a function of displacement resulting from different retardation errors of $Q W P$ $\left(T_{S}=0.002, R_{P}=0.05, R S=0.998, T_{P}=0.95, b=0.1\right.$, and $\left.\delta=3^{\circ}\right)$. The inset shows the $3 D$ plot of nonlinear error. 


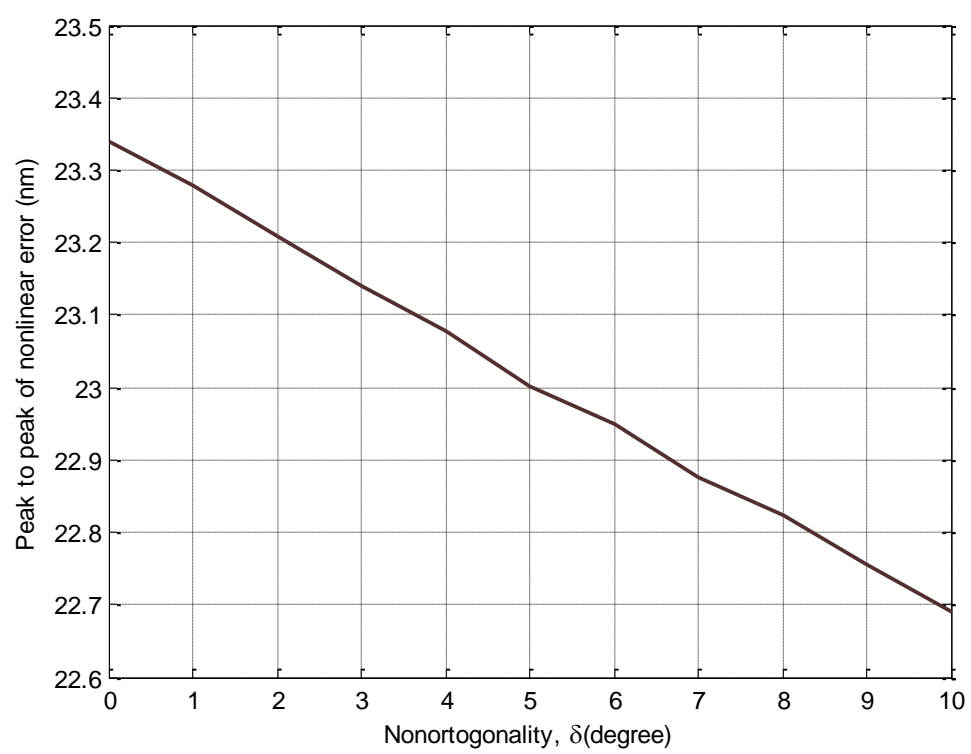

Figure 8. The peak-to-peak of nonlinear error as a function of non-orthogonality $\left(T_{S}=0.0001, R_{P}=0.05, R_{S}=0.998\right.$, $T_{P}=0.95, b=0.1$, and $\left.\varepsilon=0.05\right)$.

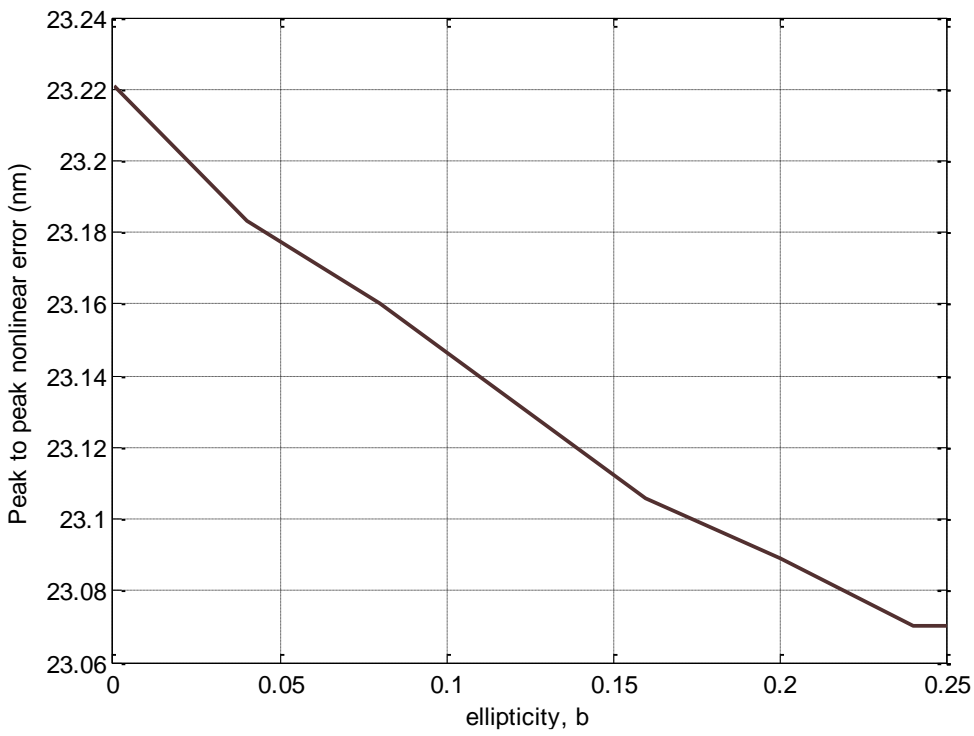

Figure 9. The peak-to-peak of nonlinear error as a function of ellipticity $\left(T_{S}=0.002, R_{P}=0.05, R_{S}=0.998, T_{P}=0.95, \delta=3^{\circ}\right.$, and $\varepsilon=0.05)$.

The effect of ellipticity and non-orthogonality are simulated and plotted in Figs. 8 and 9. The peak-to-peak of nonlinear error is plotted by changing the ellipticity from 0.05 to 0.25 and by changing the non-orthogonality of polarized beam from 0 to $9^{\circ}$. It can be seen that the ellipticity and non-orthogonality have small effect on the nonlinearity.

The calculation for negative first-order diffracted beam is as:

$$
\begin{aligned}
& \mathrm{I}_{\mathrm{PD}_{1}}^{-}=\mathrm{u}_{0}^{2}\left[1-\sin \left(-\Delta \varphi_{\mathrm{x}}+\Delta \varphi_{\mathrm{z}}\right)\right] \\
& \mathrm{I}_{\mathrm{PD}_{2}}^{-}=\mathrm{u}_{0}^{2}\left[1+\sin \left(-\Delta \varphi_{\mathrm{x}}+\Delta \varphi_{\mathrm{z}}\right)\right] \\
& \mathrm{I}_{\mathrm{PD}_{3}}^{-}=\mathrm{u}_{0}^{2}\left[1+\cos \left(-\Delta \varphi_{\mathrm{x}}+\Delta \varphi_{\mathrm{z}}\right)\right] \\
& \mathrm{I}_{\mathrm{PD}_{4}}^{-}=\mathrm{u}_{0}^{2}\left[1-\cos \left(-\Delta \varphi_{\mathrm{x}}+\Delta \varphi_{\mathrm{z}}\right)\right] \\
& \mathrm{T}_{\mathrm{X}-1}=\frac{\mathrm{I}_{\mathrm{PD} 2}^{-} \mathrm{I}_{\mathrm{PD} 1}^{-}}{\mathrm{I}_{\mathrm{PD} 3}^{-}-\mathrm{I}_{\mathrm{PD} 4}^{-}}=\tan \left(-\Delta \varphi_{\mathrm{x}}+\Delta \varphi_{\mathrm{z}}\right)
\end{aligned}
$$


We can calculate the displacement in X- and z-directions by using Eqs. (15) and (19) as follow [23]-[24]:

$$
\begin{aligned}
& \Delta \varphi_{\mathrm{X}}=\frac{1}{2}\left[\tan ^{-1} \mathrm{~T}_{\mathrm{X}+1}-\tan ^{-1} \mathrm{~T}_{\mathrm{X}-1}\right]=\frac{2 \pi}{\mathrm{g}} \Delta \mathrm{x} \\
& \Delta \mathrm{x}=\frac{\mathrm{g}}{4 \pi}\left[\tan ^{-1} \mathrm{~T}_{\mathrm{X}+1}-\tan ^{-1} \mathrm{~T}_{\mathrm{X}-1}\right] \\
& \Delta \varphi_{\mathrm{z}}=\frac{1}{2}\left[\tan ^{-1} \mathrm{~T}_{\mathrm{X}+1}+\tan ^{-1} \mathrm{~T}_{\mathrm{X}-1}\right]=\frac{2 \pi}{\lambda}(1+\cos \psi) \Delta \mathrm{z} \\
& \Delta \mathrm{z}=\frac{\lambda}{4 \pi(1+\cos \psi)}\left[\tan ^{-1} \mathrm{~T}_{\mathrm{X}+1}+\tan ^{-1} \mathrm{~T}_{\mathrm{X}-1}\right]
\end{aligned}
$$

Identically, for displacement in $y$-direction we have:

$$
\Delta \mathrm{Y}=\frac{\mathrm{g}}{4 \pi}\left[\tan ^{-1} \mathrm{~T}_{\mathrm{Y}+1}-\tan ^{-1} \mathrm{~T}_{\mathrm{Y}-1}\right]
$$

\section{Conclusion}

The effects of imperfect laser source and imperfect optical components including PBS and QWP on the nano-displacement measurement of laser encoder have been investigated. The intensity of interference signal on each photodetector is obtained by using the Jones matrices analysis. The nano-displacements in $\mathrm{x}, \mathrm{y}$, and $\mathrm{z}$ directions were calculated by using the intensity of interference signal. The periodic nonlinear error from optical loss of polarized beam in PBS, retardation error in quarter-wave plates, elliptically and non-orthogonality in laser source have been modeled and simulated. It can be seen that optical lose for polarized beam at the PBS and retardation error in QWPs caused additional phase difference in the output of detectors. The peak-topeak nonlinear error from these imperfect components and laser source is obtained as 14.82 $\mathrm{nm}$, considering typical values of transmittance and reflectance coefficients of PBS, different retardation errors of QWP, and ellipticity and non-orthogonality.

\section{References}

[1]. W. Gao, S.W. kim, H. Boss, H. Haitjema, Y.L. Chen, X.D. Lu, W. Knapp, A. Weckemann, W.T. Estler and H. Kunzmann, 2015, "Measurement technologies for precision positioning", CIRP AnnalsManufacturing Technology, 1407 No. of pages 24.

[2]. C. Lee, S. Lee, 2013, "Multi-degree-of-freedom motion error measurement in an ultra-precision machine using laser encoder - Review", Springer Journal of Mechanical Science and Technology, vol. 27:141-15.

[3]. W. Gao, Y. Saito, H. Muto, and Y. Shimizum, 2011, "A three-axis autocollimator for detection of angular error motions of a precision stage", CIRP
annals-Manufacturing technology, vol.60: 515518.

[4]. Y. Saito, Y. Araiand, W. Gao, 2009, "Detection of three-axis angles by an optical sensor", Sensors and Actuators A, vol.150: 175-183.

[5]. S. Olyaee, S. Mohammadnejad, 2007, “Design and simulation of velocity and displacement measurement system with sub nanometer uncertainty based on a new stabilized laser Doppler interferometer", Arab. J. Sci. Eng, vol.32: 90-99.

[6]. L.M .Sanchez-Brea, T. Morlanes, 2008, "Metrological errors in optical encoders", Measurement Science and Technology, vol. 19: $115104(8 p p)$.

[7]. C.B. Leem, G.H. Kim, S.K. Lee, 2012, "uncertainty investigation of grating interferometry in six degree-of-freedom motion error measurements", International Journal of Precision Engineering and Manufacturing, vol.13, no.9: 1509-1515.

[8]. C.C. Wu, J.SH. Yang, CH.Y. Cheng, Y.Z. Chen, 2013, "Common-path laser encoder", Sensors and Actuators A vol. 189: 86-92.

[9]. C. Wu, C. Liao, Y. Chen, J. Yang, "Common-path laser encoder with Littrow configuration", 2013, Sensors and Actuators A, vol. 193: 69-78.

[10]. S.J.A.G. Cosijns, H. Haitjema, and P.H.J. Schellekens, 2002, "Modeling and verifying nonlinearities in heterodyne displacement interferometry", Precision Engineering, vol. 26: 448-455.

[11]. S. Olyaee, T. H. Yoon, and S. Hamedi, 2009, "Jones matrix analysis of frequency mixing error in three -longitudinal-mode laser heterodyne interferometer", IET Optoelectronics, vol. 3: 215224.

[12]. S. Hamedi, S. Olyaee, and R. Ebrahimpour, 2009, "Modeling of nonlinearity in nanotechnology interferometric system using neural networks 
ensemble", $1^{\text {st }}$ Int. Conf. on optics \& Laser. Eng: 262-267. Isfahan, Iran.

[13]. S. Olyaee, M.S.E. Abadi, S. Hamedi, and F. Finizadeh, 2010, "Use of adoptive RLS, LMS, and LNMS algorithms for nonlinearity modeling in a modified laser interferometer", Front. Optoelectron. China (FOC), vol.3: 264-269.

[14]. T. keem, S. Gonda, L. Misumi, Q. Huang, and T. Kurusawa, 2004, "Removing nonlinearity of homodyne interferometer by adjusting the gains of its quadrature detector systems", Applied Optics, vol.43 No.12: 2443-2448.

[15]. T. Keem, S. Gonda, L. Misumi, Q. Hung and T. Kurosawa, 2005,"Simple, real time method for removing the cyclic error of homodyne interferometer with a quadrature detector system", Applied Optics,vol.44 No.17:3492-3498.

[16]. Y. Deng, J. Chai, X. Li, Y. Wu, and G. Xu, 2008, "Polarization mixing error in transmission ellipsometry with two acousto-optical modulators", Optical Engineering, vol.47(7):0776011-0776016.

[17]. S. Olyaee, and A. Gorgani-Firoozjah, 2015, "A mathematically-based model for evaluating the periodic nonlinearity of laser encoder for nanodisplacement measurements", Romanian Review Precision Mechanics, Optics and Mechatronics, vol. 24, no. 2: 66-73.

[18]. S. Olyaee, A. Gorgani Firoozjah, and A. Naraghi, 2017, "Mathematically modeling of imperfect polarizing-beam splitter in laser encoders for automotive applications", The 5th Int. Conf. on
Control, Instrumentation and Automation (ICCIA2017): 1-4. Shiraz, Iran.

[19]. S. Olyaee and A. Gorgani Firoozjah, 2015, "Modeling the nonlinearity of polarizing beam splitters in nano-displacement measurement of laser encoder using Jones matrix analysis", The 13th Int. Conf. on Telecommunications: 1-6. Graz, Austria.

[20]. A. Kimura, W. Gao ,W. Kim, K. Hosono, Y. Shimizu, L. Shi,and L. Zeng, 2012, "A subnanometric three-axis surface encoder with short-period planar gratings for stage motion measurement", Precision Engineering, vol.36: 576-58.

[21]. A. Kimura, W. Gao, Y. Arai, and Z. Lijiang, 2010, "Design and construction of a two-degree-offreedom linear encoder for Nano-metric measurement of stage position and straightness", Precision Engineering, vol.34: 145-155.

[22]. C.B. Lee, G.H. Kim, S.K. Lee, 2011, "Design and construction of a single unit multi-function optical encoder for a six-degree-of-freedom motion error measurement in an ultra-precision linear stage", Measurement Science and Technology, vol.22:105901(8pp).

[23]. X. Li, W. Gao, H. Muto, Y. Shimizu, S. Ito, S. Dian, 2013, "A six-degree-of-freedom surface encoder for precision positioning ofa planar motion stage", Precision Engineering vol.37:771-778.

[24]. W. Gao, A. Kimura, 2007, "A three -axis displacement sensor with nanometric resolution", Annals of the CIRP, vol.56: 529-532. 